\title{
Entre a tradiçāo e a inovaçāo: o IHGB e a escrita biográfica nas primeiras décadas republicanas
}

\author{
Between tradition and innovation: the IHGB and biographical \\ writing in the early republican decades
}

\author{
Alexandre de Sá Avelar a \\ E-mail: alexandre.avelar@uol.com.br \\ https://orcid.org/0000-0002-1441-2087 (iD
}

a Universidade Federal de Uberlândia, Faculdade de Artes, Filosofia e Ciências Sociais, Instituto de História, Uberlândia, MG, Brasil

\section{RESUMO}

Ao longo de todo o período imperial, o gênero biográfico exerceu um expressivo papel na operação historiográfica do Instituto Histórico e Geográfico Brasileiro (IHGB), cujos sócios viam nas narrativas dos indivíduos ilustres não apenas guias exemplares para o presente e para o futuro, mas também uma modalidade de preservação do que era considerado relevante no passado nacional. Esses objetivos se alteraram sensivelmente com 0 advento do regime republicano? A queda da Monarquia redefiniu o estatuto do gênero biográfico entre os sócios da velha instituição? O presente artigo, ao analisar uma parte da produção biográfica do IHGB, nas duas primeiras décadas republicanas, tem como principal objetivo responder a essas questões.

\section{PALAVRAS-CHAVE}

Biografia; Instituto Histórico e Geográfico Brasileiro; História

\section{ABSTRACT}

The biographical genre was crucial in the historiographical operation of the Brazilian Historical and Geographical Institute (IHGB) during Brazil's imperial period. The Institute's members members saw in the narratives of illustrious individuals not only exemplary guides for their present and future, but also a way to preserve what was considered relevant in the national past. Did these goals change significantly with the advent of the republican regime? Did the fall of the Monarchy redefine the status of the biographical genre among the members of the old IHGB? This article seeks to answer these two questions through the analysis of part of the biographical production of IHGB in the first two republican decades.

\section{KEYWORDS}

Biography; Brazilian Historical and Geographic Institute; History 


\section{O tempo desorientado: a proclamaçāo da República e o IHGB}

Ao tomar a palavra na sessão de 29 de novembro de 1889, o presidente do Instituto Histórico e Geográfico Brasileiro, Joaquim Norberto de Souza Silva, elevou-se diante de quinze presentes. O número era bastante reduzido, se comparado aos momentos áureos da agremiação, quando várias dezenas de letrados discutiam entusiasticamente uma grande quantidade de assuntos, procediam à leitura de inúmeras obras de história e geografia, homenageavam sócios recém-falecidos e celebravam o ingresso de novos. Aos ouvintes, certamente consternados, Souza e Silva anunciou:

Senhores! Imperiozo dever do meo cargo me força a annunciarvos que jamais $n$ 'essa cadeira se assentará aquelle que durante quarenta anos desempenhou verdadeiramente o título de protector de nossa associação, elevando-a à face das nações mais cultas a grande consideração, que goza actualmente. Das actas das sessões dos nossos trabalhos e das nossas sessões magnas, celebradas na sua caza, com todo o esplendor e solenidade, consta e constara sempre, o que foi o Imperador D. Pedro II para com o Instituto Histórico, que Ihe retribuio numerozos favores com a maior gratidão, por consideral-o como seo primeiro alumno, e por tel-o sempre como seo desvelado protector.

Os que têm acompanhado a marcha dos trabalhos do Instituto Histórico durante meio seculo não podem deixar de reconhecer que so por amor da patria e da gloria aqui nos reuniamos sob o exemplo da assiduidade de quem foi entre nós o primeiro. Ao transpor aquelle limiar desaparecia o monarca, e vinha o alumno sentar-se $n$ ' esse throno da democracia e tomar parte em vossas suadas lucubrações (...) (REVISTA DO INSTITUTO HISTÓRICO E GEOGRÁFICO BRASILEIRO 1889, p. 534)ํ.

A destituição de D. Pedro II - que estivera presente na sessão anterior, do dia 7 de novembro - parecia sugerir, de forma melancólica, a interrupção de uma marcha, de um fluxo temporal ordenador da experiência de todos aqueles 
que, por mais de seis décadas, se dedicaram ao penoso e delicado trabalho de dar sentido e forma a um certo discurso sobre a nação. ${ }^{1}$ A mudança de regime político significava o rompimento com o fio da história, o sentimento de que tudo estava jogado para "fora do tempo". Souza Silva esforçavase por deslocar o Instituto das "necessidades intransigentes da política" e resguardar, talvez já pensando nas dificuldades a serem enfrentadas dali em diante, a obra indispensável conduzida por sócios abnegados e de incontestável patriotismo. Em um mesmo movimento, o discurso presidencial ratificava o mecenato do imperador, expressando profunda gratidão, e afirmava o papel ativo do IHGB, que transformava até mesmo a autoridade real em um atento aluno. Se havia reverência à figura de D. Pedro II, os trabalhos desenvolvidos pelos letrados fundavam uma vida intelectual autônoma a serviço de objetivos que transcendiam os destinos individuais. Era em nome dessa obra de gerações inteiras que os sócios do IHGB, apesar de sua confessa gratidão ao imperador deposto, não desejavam, nas palavras de Souza Silva,

se antepor de modo algum à ordem das novas couzas estabelecidas e a que nos curvamos, certos de que o governo do povo pelo povo será uma realidade para a terra à qual Deos outorgou por símbolo a cruz de sua redempção, e a quem imploramos, que a republica seja tão livre como o foi o imperio de Pedro II (REVISTA DO INSTITUTO HISTÓRICO E GEOGRÁFICO BRASILEIRO 1889, p. 535).

Apesar dos incontornáveis lamentos, a sessão prosseguiu e toda a ordem do dia foi cumprida, com nomeação de novos sócios, homenagens aos falecidos, prestação de contas, leitura de ofícios diversos. A continuidade dos trabalhos demonstrava que a instituição se mantinha firme nos seus mais nobres propósitos de produzir conhecimentos históricos úteis à nação que, agora, deveria ser reinventada. As vicissitudes da política, as turbulências e paixões advindas das ruas constituíam justamente esse outro ao qual os sócios lutavam permanentemente para se opor. Honrar os antepassados que
2 Concordo com as observações de Temístocles Cézar, para quem a nação, como articuladora do discurso sobre a história no século XIX brasileiro, não esgota as possibilidades da vida intelectual desse período, pois "um sem-número de projetos, ideias, ações, são dissimulados ou obscurecidos pela grandiosidade da Nação" (CÉZAR 2018a, p. 5). 
tanto tinham feito para a escrita da nossa história significava, sobretudo, traduzir uma expectativa de futuro: se ela não mais podia estar ligada à continuidade do Império, que, ao menos, perpetuasse o gosto pelo conhecimento do nosso passado.

O discurso do presidente da velha agremiação não disfarçava a preocupação com os rumos vindouros. Ao relembrar os grandes feitos e a vocação para a posteridade dos grandes sócios, Souza Silva procurava assegurar o futuro do IHGB diante das incertezas que o momento despertava, o que talvez explique ainda o tom moderado e conciliador com qual o novo regime era tratado. Ao tomar a palavra, o sócio João Severiano da Fonseca, nessa mesma perspectiva, afirmou que

- advento da Republica Brazileira trouxe-nos uma perda immensa e um immenso pezar: o afastamento do nosso augusto e venerando imperador. Sahio -, mas o Instituto sabe que sua retirada não foi um castigo; foi a consequencia imperiosa, imprescindivel, fatal, da nova ordem de couzas; foi uma necessidade inevitavel; foi a garantia, não só para a estabilidade da nação, como para a individualidade do imperador. E com elle seguiram todo o respeito, a estima e a veneração que os Brazileiros devem e têm a esse grande e virtuoso varão. Sahio, porque não podia ficar. Não é um decahido; é antes um aposentado; retirando-se com todas as honras e distinç̧oes (REVISTA DO INSTITUTO HISTÓRICO E GEOGRÁFICO BRASILEIRO 1889, p. 537).

A República, como inevitabilidade histórica e desfecho estabilizador da conturbada situação política do país, não apagava, por outro lado, a grandeza da figura imperial que deixava o cargo sob as bênçãos eternas dos sócios do IHGB. Se sua decadência era irreversível, o regime monárquico, entretanto, não se apresentava como um passado morto e a "aposentadoria" do monarca simbolizava apenas um afastamento sem a perda da memória de sua atuação como mecenas do Instituto. A submissão à nova ordem, defendia João Severiano da Fonseca, era mais uma demonstração do zelo do Instituto pelos interesses nacionais. 
Havia, por outro lado, divergências a respeito de uma aproximação mais efetiva em relação à República recémproclamada. Na sessão posterior, de 6 de dezembro de 1889, foi rejeitada uma proposta de nomeação de uma comissão encarregada de saudar o governo provisório republicano, o que sugere o desejo de conservar certa distância política em relação ao novo regime (REVISTA DO INSTITUTO HISTÓRICO E GEOGRÁFICO BRASILEIRO 1889, p. 546). Sob a República, de todo modo, o IHGB lutaria tenazmente pela sua sobrevivência e expressar, a todo o momento, a relevância de sua existência intelectual era uma das estratégias mais acionadas.

Ciosos dos impactos provocados pelas transformações políticas pós-1889, os integrantes do IHGB não se mostravam dispostos apenas a aceitarem - sem maiores resistências, mas também sem demonstrações entusiasmadas de assentimento - os rumos do novo regime recém-instaurado, incorporando, em suas fileiras, republicanos entusiasmados, simpatizantes e adesistas de última hora. Estavam também propensos a reavaliarem os sentidos do conhecimento histórico que produziam, adaptando-o ao turbulento presente. Como bem assinala Hugo Hruby, "as concepções sobre a História e as atividades do historiador se fragilizaram perante a alteridade de reflexões oriunda da heterogeneidade do quadro social" (HRUBY 2012, p. 266). A força do passado não bastava para alimentar as demandas de uma consciência histórica que precisava se ajustar a um momento visto, simultaneamente, com apreensão e expectativa. O horizonte de realização de uma escrita historiográfica capaz de promover coesão nacional e sentido patriótico não desaparecera. Como autoridade e tradição, o discurso da história continuava a modular as apreensões do tempo e se inscrevia como fonte de múltiplos usos nos quadros da vida política de um país que se via às voltas com a tarefa de dar novos sentidos à nacionalidade. Assim, o IHGB reafirmava seu compromisso em solidificar uma consciência cívica através das formas disponíveis de figuração do passado, mas essas, por outro lado, pareciam instáveis diante 
dos rumos dos acontecimentos. Sem uma revisão dos métodos, problemas e procedimentos, o IHGB escaparia da temível obsolescência? Seria possível que os fundamentos teóricos e epistemológicos que nutriam a operação historiográfica do Instituto permanecessem inteiramente isolados da volúpia dos acontecimentos? O que era preciso fazer para que a história continuasse sendo esse facho a iluminar o presente e a assegurar os recursos morais para as ações dos homens em prol da nação? Como revitalizar a função magistral do conhecimento do passado, tópico recorrente desde os primórdios do Instituto? Quais discursos e concepções deveriam ser incitados para que se preservasse a autonomia da prática historiadora? Essas questões transfiguravam-se em disputas intelectuais em torno das noções de história e de historiador, ao mesmo tempo em que procuravam fundar novos elementos da identidade nacional. Assim,

a concepção de história e o tipo de narrativa histórica que estariam sendo elaborados no período, portanto, decorriam, em parte, das novas exigências políticas desse novo regime. Um regime que precisava se legitimar, produzindo tanto um "passado" no qual se pudesse reconhecer e ser reconhecido, como "futuros" que pudessem ser projetados e nos quais se pudesse acreditar (GOMES 2009, p. 24).

Neste artigo, a tarefa primordial será oferecer alguns elementos que possam configurar respostas razoáveis para essas perguntas, as quais, por si mesmas, são bastante genéricas e demandam algum eixo orientador para se efetuar a análise. Desse modo, o foco será concentrado no papel da escrita biográfica entre os sócios do IHGB nas duas primeiras décadas republicanas. Tal escolha decorre do próprio papel da biografia como uma questão epistemológica e política decisiva entre os sócios do Instituto. Desde sua fundação, o IHGB inscreveu seu projeto historiográfico nos marcos de uma construção intelectual, com base na qual o passado, lido como exemplaridade, deveria coexistir com a percepção do novo, ou seja, da nação que surgia como o horizonte dos homens e das 
mulheres daquele tempo. Os esforços dos letrados do velho Instituto instituíam os contornos e sentidos de uma retórica da nacionalidade, compreendida como

um conjunto de estratégias discursivas que, malgrado a natureza dispersiva dos seus elementos constituintes, foi utilizada para persuadir os brasileiros de que, a despeito da natureza heterógena e compósita da sua formação social, compartilhavam um passado comum e, consequentemente, igual origem e identidade (CEZAR 2018b, p. 20).

As biografias apresentavam homens ilustres que encarnavam os valores coletivos celebrados pela sociedade política monárquica em consonância com seu projeto de edificação de um sentimento nacional em sintonia com os tempos novos pós-1822. A construção dessa galeria de notáveis afinava-se ainda com os anseios de objetividade e de rigor documental que moviam os literatos na elaboração de uma operação historiográfica lastreada pelas perspectivas mais gerais da história magistra vitae. Assim, "a possibilidade de se atribuir à nação uma identidade original, um espírito próprio e irredutível ao das demais, serviria de fundamento para a historiografia romântica e nacionalista do Oitocentos e, por conseguinte, para a criação de grandes galerias biográficas nacionais" (OLIVEIRA 2011, p. 20).

Inseparável dessa função uniformizadora, as biografias oitocentistas do IHGB ambicionavam alcançar um estatuto de verdade que não diferia, em essência, das expectativas de uma moderna escrita da história. Talvez seja prudente observar que essa escrita biográfica se realizava sob a confluência de dois regimes de historicidade. Simultaneamente, o gênero biográfico fundava-se sob a perspectiva magistral - já salientada - de funcionar como elemento moral de educação dos homens, devendo também fornecer contornos históricos à nação, cuja emergência prenunciava uma ruptura e uma abertura ao futuro. Em relação a essa segunda função, a modernidade da biografia oitocentista, como praticada pelo IHGB, referendava 
as transformações da disciplina histórica no século XIX que, por obra de diversos historiadores e eruditos, tornava-se um saber submetido a determinadas regras e operações. Seus protocolos de veracidade deveriam ser acompanhados da crítica metódica e da análise rigorosa dos documentos. As narrativas dos indivíduos ilustres, apesar de sua dimensão pedagógica, próxima do registro magistral, não escapavam a essas regras. As ações humanas deveriam, além de narradas, ser documentadas. Além disso, os historiadores tornar-se-iam responsáveis por inserir a escrita de biografias no movimento da história universal, ou seja, as vidas individuais só seriam plenamente compreensíveis, se conciliadas com o estudo das forças coletivas que, sob um momento de aceleração e expansão, explicavam o destino da humanidade. Aqui reside a vitalidade da reflexão sobre a nação: o elo que vinculava, de modo mais expressivo, a narrativa biográfica a uma "noção específica de temporalidade como uma qualidade de desenvolvimento geral, intrínseca e imanente à realidade (OLIVEIRA 2015, p. 278).

As biografias constituíam, portanto, uma das múltiplas molduras intelectuais existentes pelas quais o passado da nação foi lido e relido ao longo de todo o século XIX (SOUSA 2012 , p. 16). Diante do que fora experimentado como a perda do futuro e como dissolução de uma utopia nacional que se imaginava preenchida e realizada pelo regime monárquico, convém interrogar a respeito dos usos dessa "moldura biográfica" nos primeiros anos da República. Ela poderia ainda ser mobilizada de modo efetivo, como repositório de exemplos, agora que o seu velho destinatário - o II Reinado como síntese da nação - não mais existia? As mesmas formas de compreensão das experiências dos indivíduos de outros tempos poderiam continuar sendo instrumentalizadas para dar sentido ao presente que, ademais, parecia, aos letrados do IHGB, ameaçador e incerto??

Algumas das questões que emergiram ao longo do século XIX ganhavam uma decisiva atualização. Os movimentos de uma transformação temporal que parecia indicar uma nova
30 trabalho indispensável de Lúcia Guimarães constitui-se, ainda em nossos dias, na referência central para a compreensão da vida institucional e intelectual do IHGB durante as primeiras décadas republicanas. Esses primeiros momentos foram, como se poderia imaginar, de crescentes dificuldades, provocadas deliberadamente pelo novo governo com o intuito de sufocar financeiramente a tradicional instituição através da sensível redução das subvenções públicas (GUIMARÃES 2007). 
aceleração poderiam ser efetivamente representados na escrita biográfica? A narração de vidas individuais ainda configurava formas de entendimento de realidades sociais mais amplas e complexas? Se as biografias publicadas nas páginas da RIHGB permitiam traçar uma galeria de homens ilustres que demonstravam certa continuidade entre passado e presente a herança positiva da presença portuguesa -, quais as razões para que elas continuassem a ser escritas em uma época que se caracterizava justamente por uma ruptura na ordem do tempo?

Feitas essas perguntas, obviamente introdutórias aos desdobramentos das investigações aqui desenvolvidas, gostaria de formular a hipótese da centralidade do gênero biográfico na revitalização da operação historiográfica do IHGB pós-1889, bem como nos modos pelos quais a experiência de aceleração histórica, "a aguda percepção da finitude" (ARAÚJO 2008, p.187), foi sentida, avaliada e traduzida em seus escritos. A moldura biográfica foi peça decisiva na preservação do ethos do IHGB como um local de homens distintos (que biografavam outros distintos), reforçando as expectativas de separação em relação ao mundo de "fora" da instituição. A biografias continuavam a ser formas discursivas fundamentais para narrar o passado não apenas pelo volume em que ainda eram publicadas, mas, sobretudo, por disponibilizar temas que expressavam boa parte das inquietações dos letrados em relação ao futuro da escrita da história após a derrocada do mecenato imperial. A noção de "moldura" é aqui usada para refletir sobre as formas de nomeação e de unidade do que é narrado, ou seja, dispositivos que são acionados para configurarem um vocabulário e uma semântica úteis ao conhecimento do passado (SOUSA 2012, p. 22).

A continuidade da tradição acadêmica do Instituto, ou seja, a manutenção de uma ambiência marcada por certos ritos tanto quanto por certos preceitos científicos, não se realizaria a partir da repetição acrítica e pouco zelosa do regime biográfico anterior. Aqui reside outra questão central: para assegurar sua 
sobrevivência como um lugar de distinção historiográfica, o IHGB realizou uma depuração do gênero biográfico em que alguns elementos vitais (a função magistral, o senso ético de justiça com os mortos, a acuidade metodológica) constituíram uma moldura que, por outro lado, não aprisionava inteiramente o novo quadro de produção intelectual que se abria para reflexões que levassem em conta, por exemplo, novos personagens para além dos grandes homens, críticas aos modelos antigos, inspirados em Plutarco, ou mesmo algumas discussões mais sofisticadas sobre as relações entre indivíduo e meio social.

\section{A "moldura biográfica" do IHGB: entre permanências, tensōes e inovaçōes}

No contexto da vida intelectual oitocentista, as narrativas biográficas tinham lugar assegurado na clássica seção Biografias dos brasileiros distintos por letras, armadas e virtudes, que passou a figurar nas páginas da Revista do Instituto Histórico e Geográfico Brasileiro (RIHGB) a partir de 1839, estendendose até o final do regime monárquico. Apenas nos dez primeiros anos de publicação da seção, foram produzidas 72 biografias, o que sugere, mais uma vez, a importância do gênero para a construção das bases de uma história nacional. Há um declínio sensível entre os anos 1850-1860, quando somente 18 trabalhos biográficos surgiram nas páginas da Revista. No período compreendido entre 1861 e 1882, as biografias totalizam 53 estudos, e até o final do século XIX, verifica-se uma nova retração, com o aparecimento de 25 outras. Ao todo, entre os anos de 1839 e 1899, os sócios e literatos do IHGB foram responsáveis pela publicação de 168 biografias.

Nas duas primeiras décadas republicanas, foram produzidos 40 trabalhos biográficos ${ }^{3}$, queda relativamente baixa, se comparada aos anos 1869-1889, quando os sócios do Instituto apresentaram 50 biografias nas páginas da sua principal publicação. Nos dois períodos examinados - as duas décadas anteriores à queda da Monarquia e as duas posteriores -, verificou-se a ausência de textos biográficos
4 Os trabalhos de natureza biográfica do IHGB possuíam características diversas: eram necrológios, ensaios biobibliográficos, artigos do tipo "a biografia de", homenagens etc. 
nas páginas da RIHGB durante apenas três anos. Esses dados, em conjunto, sugerem que, para os letrados do IHGB, o gênero biográfico constituía ainda um problema historiográfico de primeira ordem, que mobilizava dezenas de autores no desafio de compreender as diversas formas de experiência do tempo. A biografia permanecia como fornecedora de uma semântica e de uma linguagem que sintetizavam questões decisivas para a escrita da história. Percebe-se aqui, deste modo, que uma certa herança biográfica se tornava disponível aos literatos que viveram a transição para a República. Os usos dessa moldura existente, com seus conceitos, formas de compreensão e modos de escrita, constituem um tópico de inegável importância.

Os textos publicados na RIHGB não eram especialmente zelosos com o estabelecimento de contornos teóricos mais claros ou de reflexões epistemológicas mais fundamentadas. $\mathrm{Na}$ maior parte das biografias do período aqui abordado, a narrativa abria-se diretamente nos momentos iniciais da vida do personagem (predominantemente ainda um "homem ilustre"), sem quaisquer prenúncios introdutórios. A herança intelectual legada pelas gerações anteriores parecia justificar-se por si mesma e os novos trabalhos biográficos reatualizavam, a seu modo, objetivos, premissas e pressupostos já estabelecidos. Assim, em um artigo sobre o Visconde de Mauá, J. C. de Souza Ferreira afirmava:

Ao recordar nestas modestas paginas os factos principaes da vida deste homem illustre - de quem ser orgulhara ser mãe qualquer das nações mais adiantadas - levantam-se ante nosso espírito, rompendo o véo sombrio do passado, que hoje parece remoto, os varões notaveis e os grandes acontecimentos que constituem a historia do Brazil em sua phase luminosa.

Effectivamente a existencia de Irinêo Evangelista de Souza estendeu-se pelo longo periodo que vae de 1813 a 1889, e seu nome ficou ligado, não só ao desenvolvimento economico do Brazil, mas tambem a alguns problemas de natureza politica em que seu grande prestigio e sua força real foram elementos preponderantes. 
Descrever, posto que perfunctoriamente, quadro tão grandioso, fora, para quem traça essas linhas, ardua tarefa ainda out 'ora, quando a penna lhe era amiga e socia fiel; hoje, porém, a mão já incerta e os olhos escurecidos mal podem dar pallido esboço da vida de um homem, que bem merecêo da pátria e da humanidade e que, por ter sido tão grande e bom, nos dias da opulencia, como na noite da adversidade, conquistou a estima e o respeito dos contemporaneos e fez jus à gratidão dos pósteros.

A geração de hoje, ouvindo contar a vida tão útil e nobre de Irinêo Evangelista de Souza, Visconde de Mauá, procura em vão, nas praças do Rio de Janeiro, o monumento que ateste a gratidão nacional a este heroe do trabalho (FERREIRA 1900, p. 74-75; 136).

Como gênero discursivo, a biografia deveria fixar a memória dos homens ilustres, tornar-Ihes monumentos dignos de serem recordados pela posteridade. Ela se impunha como um imperativo ético, como um dever dos vivos em relação aos mortos, como uma modalidade de realização da justiça. Esse programa se perpetuou, em seus aspectos fundamentais, após a proclamação da República, fundamentando, por exemplo, o reaparecimento da seção Biografias dos brasileiros distintos por letras, armadas e virtudes em 1900. A iniciativa não prosperou, mas merece menção pelo fato de ter ressurgido sem qualquer alusão ao empreendimento pioneiro de 1839. Nenhuma palavra remetia à antiga filiação, como se a republicação da seção falasse por si mesma. As duas biografias publicadas (de Francisco Manoel Chaves Pinheiro, por Moreira de Azevedo; e de Basílio Carvalho Daemon, por seus filhos, capitão Ticiano Corregio Daemon e tenente Daemon) receberam uma única justificativa: elas retirariam do esquecimento personagens de grande importância no período imperial (REVISTA DO INSTITUTO HISTÓRICO E GEOGRÁFICO BRASILEIRO 1900, p. 165-186). Nesse novo contexto letrado, a dimensão magistral das narrativas individuais não perdera o sentido e continuava informando as intenções éticas e morais de muitos textos. Do mesmo modo, mantinham-se as expectativas de que a escrita biográfica pudesse dizer algo a mais do que a vida de um indivíduo. Ela deveria ser, igualmente, capaz de lançar 
luz sobre toda uma época, sublinhando seus aspectos mais importantes e seus sistemas normativos mais expressivos. Em outras palavras, o estudo biográfico demandava a articulação com a temporalidade ampliada de uma história universal que impunha movimentos que moldavam a experiência no tempo. No discurso de comemoração pelos 53 anos da agremiação, pronunciado em 15 de dezembro de 1901, o presidente do IHGB, Olegário Herculano d'Aquino Castro, apontava para essa linha de continuidade que subsistia no gênero biográfico:

Ides ouvir o elogio biographico dos consócios que finaram-se, proferido pelo eloquente orador do Instituto com o brilho e erudição que realçam as suas bellas orações, e podereis por ahi avaliar quão justo e intenso é o pezar que nos contrista.

O elogio dos homens bons que da sua vida nos deixaram honrosa e veneranda memoria não é um simples obsequio; é um rigoroso dever sempre cumprido com profundo e respeitoso affecto; uma justa homenagem tributada em nome da patria ao verdadeiro merito: é ainda uma licção sempre opportuna de doutrina e de experiencia com que educamos o nosso espírito e poderoso estímulo a que sejam seguidos os exemplos que nos foram dados (D'AQUINO E CASTRO 1901, p. 327).

A referida herança era marcada não apenas pelas formas discursivas de elaboração biográfica já conhecidas e atualizadas pelos sócios do Instituto, mas também, ao menos nos primeiros volumes da RIHGB publicados no regime republicano, por certas interdições que atestavam a força do passado monárquico da instituição. No relatório das atividades de 1889-1890, Teixeira de Mello relembra que, em 26 de abril de 1889, o Instituto, em sessão ordinária, aprovou a realização de uma solenidade de comemoração do centenário da morte do poeta Cláudio Manoel da Costa. Como se poderia esperar, o documento mencionava diversas virtudes do inconfidente que mais do que justificavam a celebração: seu amor pela liberdade, seu ávido patriotismo, seu talento literário que teria precedido Bocage, sua condição de mártir de uma revolução, entre outras que demonstravam que o Instituto sabia "honrar a memória dos 
nossos mortos ilustres". O republicanismo de Cláudio Manoel da Costa, porém, não foi celebrado - sequer mencionado como uma de suas qualidades cívicas. Entre os modelos de conduta que deveriam ser perpetuados como elementos de uma genuína educação patriótica, o apreço à República era ainda um tema sensível e mesmo evitado por muitos sócios (REVISTA DO INSTITUTO HISTÓRICO E GEOGRÁFICO BRASILEIRO 1899, p. 565-566).

Por outro lado, essa herança não era assumida sem certo esforço de adequação aos desafios do presente. Um deles residia no crescente papel desempenhado pelo pan-americanismo, desdobramento do próprio movimento republicano que sinalizou uma maior aproximação em relação aos vizinhos continentais. Gabriela Correa da Silva, em tese de doutorado, abordou as formas pelas quais a biografia de Alexandre Gusmão (16581753) foi reapropriada - e republicada - pelo Instituto como forma de subsidiar as investidas políticas do Estado brasileiro em relação à complexa questão pan-americana (SILVA 2019, p. 229). A atuação do conhecido diplomata passou a ser objeto de interesse entre os letrados do IHGB e alguns textos ilustram significativamente esse movimento de ressignificação biográfica em função de disputas do presente e da conformação de uma ideologia pan-americana. Em 1902, é republicado o longo artigo de José Feliciano Fernandes Pinheiro, o Visconde de São Leopoldo, intitulado "Da vida e feitos de Alexandre Gusmão e de Bartholomeu Lourenço de Gusmão". O texto apareceu inicialmente em 1841, quando o seu autor era presidente do IHGB, e destaca, sobretudo, o papel que o conhecido diplomata exerceu na delimitação das fronteiras territoriais, especialmente a atuação na assinatura do Tratado de Madri, de 1735.

Hum serviço da maior transcendencia, que alcançará seu nome nos Fastos do Brasil, foi o primeiro gisamento geral das nossas raias no Tratado de Limites de 13 de Janeiro de 1750. De ha muito era sentida a necessidade de huma Linha Geografica, que, prevenindo futuras querelas, estremasse os dous Dominios limitrophes, os mais extensos da America Meridional; precisavãose para isso superar cumulos de difficuldades; erão ainda mal 
explorados os sertões, não bem conhecidos os rios, os montes, e todas essas balisas naturaes e indeleveis, pelas quaes convêm traçar a demarcação; nem ao menos era liquida e determinada a extensão, que do lado - Oeste - tinham as possessões Portuguezas (PINHEIRO 1902, p. 386-388).

O texto do Visconde de São Leopoldo inaugurou uma asserção bastante recorrente nas representações de Alexandre de Gusmão produzidas pelos sócios do IHGB: a do precursor da moderna diplomacia brasileira. Neste sentido, a participação exitosa no Tratado de Madri era celebrada como a demonstração de uma brasilidade nascente, antecipadora do pan-americanismo, conforme se percebe em um texto de 1914, assinado por Helvécio Carlos da Silva, originalmente apresentado no I Congresso de História Nacional.

O fato mais notável de sua vida pública foi incontestavelmente o tratado que concluiu com a corte de Espanha em 13 de Janeiro de 1750, pelo qual foram pela primeira vez demarcados regularmente os limites do nosso território, e que serviu de guia precioso para os que o Brasil veio a concluir com as nações vizinhas após a sua independência, como por mais de uma vez declarou publicamente o nosso saudoso chanceler Barão do Rio Branco, que chegou até a salientar que se não fossem os bem elaborados trabalhos de Alexandre de Gusmão o Brasil ainda estaria a braços com dificuldades bastante assustadoras para regular as suas fronteiras [...]. Como se vê daí, os dois memoráveis laudos arbitrais - o de Cleveland e o de Berna - que puseram termo às nossas pendengas de limites com a Argentina e a França foram baseados no ipsis litteris na letra do tratado de 13 de janeiro de 1750, tão brilhantemente elaborado por Alexandre de Gusmão (Apud SILVA 2019, p. 230).

A modulação biográfica de Gusmão não apenas postulava uma origem para a moderna diplomacia brasileira, como investiaIhe de sentido e densidade histórica a partir da introdução de uma matriz americanista. Sincronizava-se, desse modo, o tempo da vida do biografado com o tempo do novo regime republicano, uma operação que, se não estava livre dos riscos do anacronismo, permitia que Gusmão habitasse o presente. 
O "avô dos diplomatas brasileiros" tornava-se, assim, disponível como moldura e herança, fornecendo referências exemplares para o republicanismo pós-1889. Ainda que escapando ao escopo cronológico deste artigo, um texto de Rodrigo Octávio Langgaard Menezes escrito em 1930 - e republicado em 1941, na RIHGB - merece registro especial, por indicar um traço a mais dessa releitura da biografia de Gusmão. Aqui, o diplomata não é apenas o precursor da política americanista desenvolvida pelos governos republicanos, mas também do próprio monroísmo. O celebrado Tratado de Madri deixa de ser exclusivamente um marco do nosso precoce sentimento nacional e se torna também "a carta política da América independente".

E eu vos pergunto: - não é evidente que neste velho texto desconhecido se encontram definidos generosos princípios de alta política internacional que ultrapassam o sentimento do seu tempo? Não está nele fixado o sentimento de fraternidade americana sob os princípios de uma paz perpétua? Não se vê neles o mesmo espírito que meio século mais tarde inspirou Washington e os gloriosos formadores da grande nação norteamericana e se cristalizaram na palavra nítida e precisa de Monroe? [...]. Não se pode desconhecer, assim, que do dispositivo do Tratado de 1750 se desprendem os princípios fundamentais da mensagem americana de 1823: - a solidariedade continental pela concórdia e o alheamento da América das consequências das intrigas da política europeia, princípios fundamentais de onde decorreu o lema - A América para os Americanos (MENEZES 1941, p. 31-32).

A atuação destacada de Alexandre de Gusmão no interior desse momento precursor do monroísmo demarcava um modelo histórico que não apenas deveria ser seguidamente rememorado - Menezes menciona, mesmo equivocadamente, que Gusmão fora esquecido pelos historiadores -. mas usado como guia moral e diplomático para os homens da República. 0 último item do artigo, não por acaso, denomina-se "glorificação de Gusmão": 
Alexandre de Gusmão, em cujas veias, por sua mãe, corria o sangue americano, e cujos primeiros anos se passaram na liberdade da terra infinita da América, ante a perspectiva do mar infinito, não adaptado às tortuosidades da política européia de seu tempo, ferido e maltratado pelas intrigas da Corte, comprimido pela estreiteza do espírito clerical, tão absorvente no seu tempo que tornava irrespirável o ar fora das igrejas ou dos conventos, amando essa terra sua natal, que os azares das competições políticas e da pequenez de destino não Ihe permitiu (sic) que volvesse a ver, e desejando preservá-la da desgraça das guerras, das competições políticas, e da pequenez de sentimentos que não se explicavam na liberdade e na vastidão dos seus horizontes, procurou, com o tratado de 1750 , pondo termo às discórdias presentes, pela solução mais conveniente dos casos concretos que as haviam criado e mantido, preservar o futuro de suas consequências, imprimindo ao desenrolar da vida desses povos, o sentimento de fraternidade e de independência que cria e mantém o respeito recíproco e o espírito de solidariedade.

(...) Certamente, com a intenção desses princípios num tratado, dando-Ihes relevo universal e eficácia real, Alexandre de Gusmão traçou, no que entende como os mais naturais e legítimos interesses da América, a diretriz segura e vitoriosa de sua política internacional.

(...) Acentuando o verdadeiro e benéfico significado do Panamericanismo, exaltando-Ihes os fecundos resultados, não esqueçamos, entretanto, de proclamar bem alto o nome do seu mais remoto propugnador, Alexandre de Gusmão, filho do Brasil (MENEZES 1941, p. 33-34; 39).

A elevação de Alexandre de Gusmão a predecessor da política republicana americanista foi o resultado da intervenção de diversos intelectuais ligados ao IHGB, que mantiveram a aposta biográfica como uma modalidade de escrita da história capaz de se adaptar às novas condições políticas e intelectuais abertas a partir de 1889 . Os usos da biografia permitiriam, mais uma vez, reconfigurar as dimensões da nacionalidade, sinalizando para suas feições republicanas em meio a impasses, crises e incertezas quanto ao futuro. Assim como nas biografias oitocentistas publicadas pelo IHGB, esboçavase um passado que pudesse ser assimilado e compartilhado, revelando a "marcha das forças coletivas e a identificação 
dos seus protagonistas" (OLIVEIRA 2015, p. 278). Essa força homogeneizante da biografia não significava, por outro lado, a inexistência de nuances ou diferenças de pontos de vista, ainda que sutis, entre os sócios do IHGB a respeito do tratamento que deveria ser conferido a Alexandre de Gusmão. Um exemplo interessante é o parecer que uma comissão emitiu a respeito da publicação de um texto de Cesar Feliciano Xavier, originalmente proferido na assembleia inaugural do Instituto Pan-Americano de Geografia e História em 1933. Em posição semelhante à de outros autores, Xavier identifica no Tratado de Madri o "apanágio do adiantado da civilização americana", antecipando em um século a Doutrina Monroe. Assim, era também adequado atribuir ao Brasil "a primazia daquilo que se chamou depois espírito pan-americano". Como por sua atuação destacada na assinatura do tratado, Gusmão era exaltado como um "insigne Estadista Americano", um precoce formulador da política americanista que se tornaria o registro definidor da identidade continental. De acordo com o parecer, Alexandre de Gusmão foi

(...) incontestavelmente, no cenário da política americana, o primeiro estadista em cujo cérebro luziram as ideias panamericanistas, com acentuado espírito de brasilidade, com relação ao Império Lusitano. Precursor de Monroe e Bolívar, na política americanista "foi provavelmente no mundo e seguramente na América, o estadista que por inigualável política de fraternidade não só adjudicou à sua pátria cerca de cinco milhões de quilômetros quadrados [...] como também, assim agindo, ao mundo civilizado irrecusável prova deu, de que se o continente colombiano é o hemisfério da paz, como preconizara - nosso grandíloquo Joaquim Nabuco, pan-americanista fulgurante, irrecusavelmente é o Brasil o pioneiro máximo dessa glória ímpar na política dos povos [...]". Fez, pois, obra meritória o autor da tese em estudo, trazendo novamente à baila a figura empolgante de Alexandre de Gusmão, que nunca é demais lembrar e louvar e cuja efígie por feliz inspiração do Barão de Rio Branco, figura na galeria dos grandes americanos, no Palácio do Itamaraty. Pelos motivos expostos, a contribuição do Sr. Comandante Cesar Feliciano Xavier, delegado do Club Naval, é digna do melhor acolhimento por parte desta douta Assembleia. Rio de Janeiro, 28 de dezembro de 1932. 
- A. Tavares de Lyra, presidente. - Rodrigo Octávio Filho, relator (Delegado da República Dominicana. Membro efetivo do Instituto Histórico e Geográfico Brasileiro) - Octavio N. Brito - Felix M. P. Sampaio - Rodolfo Garcia - Souza Docca - Alcides Bezerra Alfredo Ferreira Lage - Mucio Vaz - Vanderley Pinho - Vicente Valdés Rodrigues - H. A. Torres (Apud SILVA 2019, p. 232).

Para a comissão, Gusmão certamente tinha lugar cativo na galeria dos grandes pan-americanistas em função do papel desempenhado no Tratado de Madri. Por outro lado, a realização de uma política que transformasse o continente em um "hemisfério da paz" é mais o resultado do "acentuado espírito de brasilidade" do diplomata do que um conjunto de iniciativas pensadas deliberadamente a priori. Se o Brasil foi "o pioneiro máximo dessa glória ímpar na política dos povos", isso se deveu à identificação antecipadora de uma ideia de nação e à consequente defesa dos seus interesses. Assim, os usos da biografia de Gusmão, nessa chave de leitura, se deram "mais no sentido de nacionalizar a história pan-americana - porquanto é oferecida uma posição de imenso destaque ao Brasil -, do que de pan-americanizar a história nacional" (SILVA 2019, p. 233).

A consagração de Gusmão operava ainda no registro do varão ilustre, sujeito heroicizado pelos feitos realizados e que eram transformados, através das narrativas biográficas, em exemplos capazes de inspirar e orientar os homens. Entretanto, essa moldura biográfica não era tão rígida. Tristão de Araripe, líder republicano, escrevendo em 1894, alertava para a necessidade de a instrução pública ser guiada pelo "doutrinamento da história". Assim, os homens teriam condição de compreenderem "o que a pátria é e o que pode ser". Apesar da reafirmação da função da biografia (o historiador dever dar "os traços característicos do verdadeiro herói, oferecendo à imaginação do leitor as feições íntimas da alma do homem egrégio"), Araripe se esforçava, por outro lado, para contrapor um modo "moderno" de escrever a história a outro, "antigo", sendo o primeiro uma história dos povos e o segundo uma história atenta aos feitos de reis e generais. A autoridade dos antigos passava assim a ser relativizada, pois haviam deixado 
narrativas incompletas, "sem os elementos da crítica e sem a soma das experiências da Idade Moderna" (ARARIPE 1895, p. 264). O modelo plutarquiano, capaz de oferecer lições e paradigmas de conduta moral, era ainda incomparável na tarefa de produzir o sentimento patriótico. A nobre inspiração que a composição de biografias poderia suscitar não impediu Araripe de ver em Plutarco a reprodução do equívoco comum aos antigos, o de considerar heróis somente aqueles que haviam se tornado célebres nos campos de batalha. Além disso, o gênero biográfico deveria obedecer escrupulosamente aos critérios de verdade objetiva e distanciada que a pesquisa moderna em história lograra construir, ainda que muitas fossem as pressões para que os temas contemporâneos - mais suscetíveis à subjetividade do historiador - também fossem objeto do labor historiográfico. Como se poderia esperar, evitavam-se as biografias de personagens cuja proximidade temporal em relação aos biógrafos pudesse colocar em risco a interpretação imparcial e acurada dos seus atos.

Mas quais eram os "verdadeiros" heróis? A fixação da memória dos atos dos homens beneméritos do passado não estava ou não deveria estar em descompasso com a concepção moderna de história que os novos tempos impunham. Se os antigos enfatizavam as individualidades, especialmente aquelas dos heróis (os "falsos"?), das guerras e dos reis, os modernos preocupavam-se com os destinos coletivos, com a história dos povos e não apenas dos indivíduos. Se havia heróis a serem celebrados, estes eram os "da paz" (estadistas, sábios, industriosos), cujas ações se conformavam mais ao desenvolvimento geral das sociedades (ARARIPE 1895, p. 285). Essa percepção afinava-se, no geral, com a conversão de Araripe, agora um dedicado defensor da causa republicana. Obedecendo às leis da história, a proclamação da República era o efeito visível já nas disputas em torno da preservação de nossas normas constitucionais em 1831. A passagem dos acontecimentos revelava, assim, um destino, um desfecho para o qual tudo parecia concorrer e se explicar. A ação da história, era, desse modo, a força que imperava sobre as 
ações individuais. Os homens e seus feitos só ganhavam seus contornos e sentidos mediante as forças inelutáveis do desenvolvimento histórico. Esse raciocínio aproximava Araripe de outro importante letrado do IHGB, Pedro Lessa, para quem "antes que um grande homem possa refazer a sociedade, é preciso que a sociedade o faça". Embora Lessa tenha sido um crítico das concepções mais romantizadas do heroísmo, que ainda alimentavam muitas biografias produzidas no interior do IHGB, sua ênfase em fatores sociais como explicativos das ações humanas não significava nenhuma adesão a alguma forma de determinismo fatalista ou a "uma física da história". Tampouco, por outro lado, elas podem ser facilmente discerníveis mesmo a partir da observação rigorosa. As limitações colocadas ao homem interferem em sua responsabilidade como indivíduo que atua no mundo, mas não $o$ freiam inteiramente. Natureza e agência se influenciam e se modificam mutuamente sem que tenhamos a exatidão absoluta dessas interações. Para Lessa,

(...) a observação quotidiana dos factos nos arrasta a confessar que os homens são resultantes dos tempos e dos logares em que vivem, estreitamente solidarios com tudo que os cerca, os precede e os segue. A hereditariedade, ou meio interno, determina-lhes o caracter e o temperamento. O meio cosmico, o meio individual e o social actuam sobre o caracter e o temperamento e os modificam.

(...) Em ultima analyse, a unica liberdade que tem o homem é a de agir (liberdade dos actos) de accordo com a sua vontade, suas predilecções, suas inclinações, de conformidade com os seus móveis e motivos. $\mathrm{E}$, sendo assim, o determinismo não destróe a individualidade, a personalidade, o conjuncto das qualidades peculiares a um individuo, e o que distinguem dos outros individuos da mesma especie. Exactamente por haver uma riqueza admiravel de factores que distinguem a constituição psychica dos individuos, e uma grande abundancia de idéas e sentimentos, de inclinações e paixões, que actuam como forças propulsoras da vontade, e por não conhecermos previamente quaes os factores e os motivos que hão de predominar em um determinado caso, é que não podemos prevêr com segurança os phenomenos voluntarios, excepto dentro de certos limites. 
(...) O determinismo não nega a individualidade, a personalidade; pelo contrario, explica scientificamente por que a constituição physica dos individuos varia, e distingue cada homem dos seus semelhantes. Ninguem ainda se lembrou, observa Schopenhauer, de se desculpar da pratica de um acto condemnavel, atribuindo exclusivamente aos motivos: todos estão certos de que a imperfeição do seu caracter contribuiu para a producção do acto censuravel. Cada um de nós está convencido de que, sob a pressão dos mesmos motivos que o levaram a practicar um ato imoral, outro individuo de mais aperfeiçoada organisação mental, de melhor educação e de intelligencia mais esclarecida e capaz de reflexão, teria procedido diversamente. As acções voluntarias de um indivíduo decorrem do seu caracter, do conjuncto de attributos que o distinguem, e consequentemente the são imputaveis. Lançam-se na conta de cada um de nós. Não devemos responder por esses actos? (LESSA 1906, p. 228; 232; 234).

A atenção cada vez maior conferida aos elementos coletivos e aos sistemas normativos que, se não anulavam, impunham limites às ações individuais, traduziram-se, em alguns autores, em elaborações mais sofisticadas sobre a noção de povo. Em um livro destinado ao ensino básico, publicado em 1890 e intitulado A história do Brasil ensinada pela biografia dos seus heróis, Sílvio Romero - tornado sócio do IHGB em 1901 - reposicionou a escrita biográfica como instrumento de uma pedagogia nacional, agora republicana, capaz de indicar os caminhos para "o aprendizado das virtudes cívicas e da história de um povo" (GOMES 2009, p. 111). A mobilização do preceito magistral da biografia vinculava-se ao velho intento de arrancar do esquecimento as vidas dos indivíduos notáveis. João Ribeiro, autor do prefácio do livro, destacava que as modulações biográficas defendidas por Romero supunham que o uso do gênero se baseava numa proeminência do geral sobre o particular, o que explicava a pertinência de uma instrução cívica ministrada por meio de exemplos de indivíduos que "fertilizavam a história da pátria". O livro se estruturava em uma ordem cronológica que se iniciava no descobrimento, deixando visível uma perspectiva evolucionista que era sintetizada pelas ações de alguns "heróis" 
cuidadosamente selecionados. Os capítulos não informam apenas a respeito dos personagens que formam esse panteão, como também avançam em direção a sínteses interpretativas, concedendo a cada século um sentido no conjunto da evolução da nação. Numa chave analítica em alguma medida destoante daquela exercitada pelos letrados do IHGB durante o período imperial, Romero defendia a ideia de que a maior contribuição que o Brasil poderia oferecer ao mundo ocidental residia na novidade do seu povo, profundamente miscigenado e que encarnava o "cosmopolitismo do futuro" (ROMERO 1890, p. 3).

Ao formular a tese de um "povo novo" e mestiço, Sílvio Romero produzia fissuras numa concepção do fazer biográfico que valorizava o voluntarismo dos grandes homens como agentes quase solitários na história do país. Ainda que esses sujeitos não estivessem ausentes da obra de Romero - lá estão narrativas biográficas sobre José Bonifácio, Hipólito da Costa, Gonçalves Dias, Deodoro da Fonseca, entre outros -, dois aspectos apresentavam-se como contrapesos que relativizavam a força dos destinos individuais. O primeiro deles era a importância conferida aos fatores que tensionavam as relações entre os indivíduos e os sistemas normativos. As vidas dos biografados eram introduzidas ao leitor por intermédio da menção ao "tempo" no qual eles haviam atuado. Esse terreno contextual não ignorava a vitalidade das ações humanas e Sílvio Romero não cansou de exaltá-las em um estilo muito próximo de Carlyle e seus heróis. Por outro lado, os indivíduos sofriam com os determinismos existentes, sobretudo aqueles ligados à força da natureza. O segundo aspecto, decorrência do primeiro, considerava a importância das "criações anônimas/ populares" que as abordagens clássicas da biografia deixavam em segundo plano. Essas formas criadoras definiam-se em função do trabalho coletivo de sucessivas gerações e não poderiam mais ser desconsideradas em qualquer estudo que tivesse o propósito de especificar o papel e as ações de sujeitos individuais, porque: 
A hero-worship de Carlyle tem o defeito de desconhecer o valor das criações populares e dar um culto por demais exagerado e sobrehumano a alguns tipos de privilegiados. Um sistema de história que não dá conta das criações anônimas é perfeitamente incompleto e falso; hoje só os espíritos retardatários desconhecem que os mais imponentes produtos da atividade humana, como a linguagem, as mitologias, as religiões, os contos, as legendas, as grandes epopeias, não são obra dos heróis, são produções anônimas. Carlyle, diante de Buckle, faz uma figura apoucada (ROMERO 1951, p. 147).

Em Sílvio Romero, a consideração do povo como sujeito histórico era um passo importante em direção a uma apreensão mais crítica das relações entre indivíduo e meio, graças a qual alguns dos pressupostos da herança biográfica do IHGB passaram a ser problematizados de forma mais densa. Embora a operação historiográfica do Instituto reforçasse a convicção de que os grandes personagens podiam elucidar melhor 0 desvendamento dos nexos lógicos entre os acontecimentos e a marcha progressiva da civilização, novos elementos críticos foram acrescentados a esse pressuposto fundamental. Em um artigo de 1892, escrito com o objetivo de traçar a trajetória histórica da Sociedade Amante da Instrução, criada no Rio de Janeiro e destinada ao cuidado de crianças pobres e órfãs, seu autor, Alfredo do Nascimento Silva, alertava para a emergência de uma multiplicidade de novos atores na "arena da história", sendo eles "os honrados operários, onerados de numerosa prole $[\ldots]$; as legiões de filhos sem pais $[.$.$] ; os$ filhos da pobreza; [...]; todos esses desgraçados que a doença invalidou; [...] finalmente, os náufragos do mundo que não puderam lutar contra os temporais" (SILVA 1892, p. 99). Esse grande contingente de indivíduos inteiramente ausentes dos grandes relatos históricos conseguira, finalmente, irromper na cena política, tornar-se visível, exigindo do historiador novas formas de compreensão do passado:

Longe vai o tempo em que a historia, deixando-se illudir pelas apparencias e fascinar pelas pompas de grandeza e pelo fausto dos potentados, limitou-se a ser a chronica dos reis, dos nobres 
e dos vultos mais salientados pelos seus títulos de gloria. Nesse tempo visava-se o throno aureolado de grandeza [...], mas não se olhava para o gigante que o sustenta em seus hombros, para esse colosso que vale tudo e a que nenhuma importancia se ligava, isto é, o povo, cuja soberania no emtanto agora se impõe (SILVA 1892, p. 102).

Essa soberania significava, sobretudo, a demanda por um outro olhar, deslocado, dos historiadores, acostumados a vislumbrar a "ostentosa riqueza (..) que no primeiro plano e mais salientado depara sua vista" (SILVA 1892, p. 97). Não era mais possível contemplar apenas "os apaniguados da sorte", os integrantes dos grupos socialmente mais favorecidos, que concentravam riquezas e privilégios de toda ordem. Atrás de toda essa opulência, "sente-se um turbilhão confuso do povo acotovelando-se nas praças" em busca da sobrevivência e de "um equilibrio eternamente irrealisavel" (SILVA 1892, p. 98). Essa massa abriga todos os tipos de caracteres, vícios e virtudes, e o estudioso que quiser compreendê-la precisa ir ao seu encontro, já que nada parece claro e nítido à primeira vista.

A multidão dos inválidos e dos necessitados opera uma força capaz de impulsionar a história que, até então, os ignorava tristemente. Os novos tempos demandavam dos historiadores a exata compreensão das tragédias desse povo que se perdia em meio à degradação, à infâmia e ao crime. Sem a intervenção decidida dos especialistas nos estudos históricos, estávamos condenados a reproduzir incessantemente nossas mazelas e a perder todas as virtudes que os pobres e miseráveis ainda teimavam em carregar. A linguagem de Nascimento e Silva não mascarava a feição higienista do seu pensamento: à higiene individual, saneadora do corpo, deveria corresponder uma higiene social, capaz de vigiar de perto a "podridão", de "queimar as pustulas sociaes, (...) fortificando os espíritos, difundindo-Ihes a instrucção, e pregando-Ihes a moral" (SILVA 1892, p. 101). 
Sem se desfazer da crença na existência de uma elite ilustrada capaz de regenerar o povo miserável e sofrido, Nascimento Silva instaura uma reflexão essencial sobre os personagens ignorados da história que eram, entretanto, dignos de figurarem nos livros e nos textos dos historiadores. Sob um ponto de vista evolucionista e tributário de um certo biologismo, o autor redimensiona os lugares das entidades coletivas, sobretudo do povo e dos indivíduos na configuração dos sistemas sociais.

Crescendo pouco a pouco e de mais a mais accentuando o seu poder, essa massa popular sacudío um dia as espaduas herculeas e os thronos tremeram em seus alicerces. Os despotas calcaram o jugo, sofreiaram o fogoso corse, e elle soffreu algum tempo, mas sempre lembrando, $n$ 'um vosear confuso, que nelle é que palpita o coração da patria.

(...) Do rapido exposto, se deduz que a verdadeira historia é o estudo da civilisação do povo, isto é, da evolução da humanidade e da physiologia social. Organismo complexo, ella fórma um todo que deve ser individualmente estudado; as raças, os povos, as tribus e as familias são os apparelhos e os orgaos deste gigantesco conjuncto, cujo ultimo termo analytico é o individuo homem, a cellula viva da sociedade. Assim como a vida do individuo é a resultante final da somma das vidas de seus componentes cellulares, assim a vida da humanidade tambem representa a somma das vidas de seus componentes, isto é, dos individuos que se congregam em familias, tribus e povos, outros tantos orgaos e apparelhos elaboradores da civilisação. A cellula é o atomo do individuo, este é a cellula da humanidade, e ella uma diminuta parcella do mundo, que por sua vez é apenas um atomo do universo!

(...) Assim tambem a biographia de um vulto, a chronica de uma época, a narrativa de um episodio, os commentarios de um facto ou o estudo de uma instituição, não formam certamente a historia, mas são os seus elementos componentes, os materiaes que ella coordenará para apreciar, julgar e formar a synthese, incorporando em doutrinas as deducções que tirar; e quando escrevemos a historia ou qualquer sciencia, vamos beber nessas fontes, vamos haurir nesses mananciaes a materia prima para taes trabalhos. (...) Como o biologista, o historiador precisa agora aplicar o microscopio para analysar a cellula social, assistir 
ao trabalho dos orgãos, apreciar a civilisação em seus fócos, como aquelle aprecia a vida em seu berço (SILVA 1892, p. 102103; 105-107).

A expressividade da ação individual, para Nascimento e Silva, só adquire pleno sentido e inteligibilidade como elemento de uma engrenagem social superior, a história, composta por forças que conduzem a humanidade segundo leis precisas e inapeláveis. Compreender esse todo é, portanto, o trabalho do "historiador-biologista", munido dos diversos elementos tidos como fontes - conformadores da civilização. Essa posição estava ainda longe de ser majoritária dentro do IHGB, mas se mostrava como portadora de um potencial crítico capaz de tensionar a moldura biográfica existente, alicerçada na concepção de "grande homem", segundo a qual, em consonância com o pensamento do filósofo francês Victor Cousin, alguns indivíduos poderiam ser considerados a síntese moral dos povos e das coletividades e também representariam aqueles que não eram visíveis na história (OLIVEIRA 2015, p. 277-278).

O estabelecimento das relações entre as dimensões coletivas da história e as ações dos indivíduos mantinha-se como uma questão historiográfica de primeira ordem para os letrados do IHGB. Nascimento e Silva introduzia uma dose de ceticismo quanto à função civilizatória que poderia se vislumbrar em certas trajetórias individuais. As glórias da nação e o sentimento patriótico não eram, agora, incompatíveis com a percepção de que o povo, e não apenas os "grandes homens", desempenhava um papel decisivo na marcha dos acontecimentos. As vidas daqueles sujeitos que supostamente encarnariam as grandes virtudes nacionais não constituíam mais modalidades de exemplaridade nem adquiriam valor pleno por si mesmas, mas apenas como elementos ou formas constituintes de uma totalidade. 


\title{
Consideraçōes finais
}

\begin{abstract}
Senhores: - Achamo-nos em um campo neutro, onde não entra a política com as suas tergiversações e subtilezas. Lá fora esbraveja de noite e de dia o ruido dos interesses desencontrados e antagonistas; o sorriso que mascára o rancor e o despeito; a phrase assucarada que encobre o pensamento; o patriotismo, que é santo e nobre, encarado por prismas diversos. Aqui o silencio de que medito; a paz e a serenidade de animo do que se afadiga por honrar o renome nacional, zelando o renome de seus filhos illustres e archivando os fatos memoraveis da história patria. Lá fora a paixão doudejante correndo atraz de phantasmas illusorios que a razão fria desvanece. Aqui a calma dos desambiciosos, que tudo antempõem ao conhecimento da verdade para a transmittir intacta (MELLO 1890, p. 561).
\end{abstract}

Essas palavras foram pronunciadas pelo sócio José Alexandre Teixeira de Mello, responsável pelo relatório das atividades da RIHGB no biênio 1889-1890, ainda sob o impacto do fim do regime monárquico e do exílio de $\mathrm{D}$. Pedro II. A política vinda das ruas, associada à desordem e ao irracionalismo, configurava uma alteridade a ser evitada, se o Instituto desejasse se manter como o guardião desinteressado dos estudos históricos e do conhecimento do passado. O presente não era apenas temido porque ameaçava, com seus ruídos e paixões, a força da objetividade e da imparcialidade exigidas ao zeloso estudioso das experiências dos homens de outros tempos. $\mathrm{O}$ ardor político do espaço público destruía as próprias condições de possibilidade do estudo da história, as formas de uma razão historiográfica tão duramente conquistada. Não obstante as reivindicações de clareza, de rigor desapaixonado e de um quase ascético espírito científico, as palavras de Mello estavam carregadas de arrebatamento e furor, talvez explicáveis pelo seu monarquismo convicto e em luto. Os anos seguintes demonstrariam, também, o equívoco de tais reivindicações.

A queda da Monarquia foi recebida pelos sócios do IHGB com um misto de temor, incertezas e desorientação. Era impreciso o que significariam esses novos tempos para 
uma instituição ainda tão arraigadamente presa ao passado imperial. Não parecia provável que o IHGB, mesmo sem aderir explicitamente ao republicanismo, pudesse fechar suas portas à colaboração de indivíduos identificados ao novo regime. Mas isso, apenas, não bastaria. Seria possível que as molduras historiográficas disponíveis, e tão laboriosamente constituídas desde 1838, servissem para normalizar a vida intelectual da velha agremiação? A aposta dos letrados do IHGB foi a de uma sistemática reafirmação da história como ciência moral, magistral, capaz de instruir os homens do presente e abri-los ao futuro. No entanto, como se tentou demonstrar ao longo deste texto, não se tratava de escutar acriticamente as vozes do passado. A exemplaridade e os ensinamentos que poderiam ser absorvidos do estudo detido, rigoroso e objetivo de outros tempos eram molduras a serem postas em confronto com 0 presente. A escrita biográfica praticada pelos sócios do IHGB não escapou a esses dilemas. Por um lado, ela remetia a um conjunto claro e estabelecido de princípios que deveriam permitir o enquadramento das trajetórias de sujeitos e varões ilustres: os grandes feitos, a dedicação à pátria, a força da exemplaridade. Por outro, assistiu-se a um adensamento epistemológico e analítico em torno de certas noções, tais como as de herói, grande homem, indivíduo, contexto, entre outras, que antes eram acionadas de maneira naturalizada. 0 turbulento mundo da política e da rua, com seus personagens anônimos e suas forças quase irrefreáveis, desejava entrar. $\mathrm{E}$ não se pode dizer que não tenha conseguido. 


\section{REFERÊNCIAS}

ARARIPE, Tristão de Alencar. Indicações sobre a História Nacional. Revista do Instituto Histórico e Geográfico Brasileiro, t. 57, parte II, p. 259-290, 1895.

ARAÚJO, Valdei Lopes de. A experiência do tempo: conceitos e narrativas na formação nacional brasileira (1813-1845). São Paulo: Hucitec, 2008.

CÉZAR, Temístocles. O que fabrica o historiador quando faz história hoje? Ensaio sobre a crença na história (Brasil, séculos XIX-XXI). Revista de Antropologia, v. 61, n. 2, p. 78-95, 2018a. DOI: 10.11606/2179-0892.ra.2018.148933. Disponível em: http://www.revistas.usp.br/ra/article/ view/148933/146996. Acesso em: 16 jul. 2019.

CÉZAR, Temístocles. Ser historiador no século XIX: o caso Varnhagen. Belo Horizonte: Autêntica, 2018b.

D'AQUINO E CASTRO, Olegario Herculano. Discurso. Revista do Instituto Histórico e Geográfico Brasileiro t. LXIV (2), p. 319-328, 1901.

FERREIRA, J. C. de Souza. Visconde de Mauá (esboço biographico). Revista do Instituto Histórico e Geográfico Brasileiro, t. LXII, p. 74-136, 1900.

GOMES, Ângela de Castro. A República, a História e o IHGB. Belo Horizonte: Fino Traço, 2009.

GUIMARÃES, Lúcia Maria Paschoal. Da Escola Palatina ao Silogeu: Instituto Histórico e Geográfico Brasileiro (1889-1938). Rio de Janeiro: Museu da República, 2007. 
HRUBY, Hugo. O século XIX e a escrita da história: diálogos na obra de Tristão de Alencar Araripe (18671895). Tese (Doutorado em História) - Programa de PósGraduação em História, Pontifícia Universidade Católica do Rio Grande do Sul, Porto Alegre, 2012.

LESSA, Pedro. Reflexões sobre o conceito de História. Revista do Instituto Histórico e Geográfico Brasileiro, t. 69 , v. 114 , p. 193-285, 1906.

MELLO, José Alexandre Teixeira. Relatório dos trabalhos annuaes de 1889 e 1890 . Revista do Instituto Histórico e Geográfico Brasileiro, t. LXIII, parte II, p. 561-565, 1890.

MENEZES, Rodrigo Octávio Langgaard. Alexandre de Gusmão e o Monroísmo. Revista do Instituto Histórico e Geográfico Brasileiro, volume 175, 1941, p 5-69.

OLIVEIRA, Maria da Glória. Biografia e historia magistral vitae: sobre a exemplaridade das vidas ilustres no Brasil oitocentista. Anos 90, v. 22, n. 42, p. 273-294, 2015.

OLIVEIRA, Maria da Glória. Escrever vidas, narrar a história: a biografia como problema historiográfico no Brasil oitocentista. Rio de Janeiro: Editora da FGV, 2011.

PINHEIRO, José Feliciano Fernandes. Da vida e feitos de Alexandre de Gusmão e de Bartholomeu Lourenço de Gusmão. Revista do Instituto Histórico e Geográfico Brasileiro, t. LXV, parte I, p. 377-423, 1902.

REVISTA DO INSTITUTO HISTÓRICO E GEOGRÁFICO BRASILEIRO, LII, parte II, 1889, 580p.

REVISTA DO INSTITUTO HISTÓRICO E GEOGRÁFICO BRASILEIRO, t. LXII, 1900, 490p. 
ROMERO, Sílvio. A história do Brasil ensinada pela biografia de seus heróis. Rio de Janeiro: Livraria Alves e Cia., 1890.

ROMERO, Sílvio. Da interpretação filosófica na evolução dos fatos históricos. Studia, Rio de Janeiro, n. 2, Ano II, p. 143-154, 1951.

SILVA, Alfredo do Nascimento. Um átomo da História Pátria: histórico da Sociedade Amante da Instrucção. Revista do Instituto Histórico e Geográfico Brasileiro, t. 55, parte II, p. 97-140, 1892.

SILVA, Gabriela Correa. Dos passados heterogêneos ao mosaico continental: pan-americanismo e operação historiográfica no IHGB republicano (1889-1933). Tese (Doutorado em História) - Programa de Pós-Graduação em História da Universidade Federal do Rio Grande do Sul, Porto Alegre, 2019.

SOUSA, Francisco Gouveia de. Proclamação e revolta: recepções da República pelos sócios do IHGB e a vida da cidade (1880-1900). Tese (Doutorado em História) Programa de Pós-Graduação em História Social da Cultura, Pontifícia Universidade Católica do Rio de Janeiro, Rio de Janeiro, 2012. 
NOTA SOBRE O AUTOR

\title{
Alexandre de Sá Avelar
}

alexandre.avelar@uol.com.br

Universidade Federal de Uberlândia

Uberlândia

Minas Gerais

Brasil

\section{ENDERECO DE CORRESPONDÊNCIA}

\author{
Alexandre de Sá Avelar \\ Universidade Federal de Uberlândia \\ Faculdade de Artes, Filosofia e Ciências Sociais, Instituto de História. \\ João Naves de Ávila, 2121 \\ Santa Mônica \\ 38400902 \\ Uberlândia, MG - Brasil
}

FINANCIAMENTO

Este artigo recebeu apoio do $\mathrm{CNPq}$ - Bolsa Produtividade.

\section{CONFLITO DE INTERESSE}

Nenhum conflito de interesse declarado.

Copyright

2020 História da

Historiografia:

International Journal

of Theory and History

of Historiography.

Este é um artigo

distribuído em Acesso

Aberto sob os termos

da Licença Creative

Commons Atribuição-

Não Com ercia I -

SemDerivações 4.0

International. 